\title{
"It's only the skin colour, otherwise we are all people": the changing face of the Australian nurse
}

AUTHORS

SOPHIA DYWILI ${ }^{1}$
LOUISE O'BRIEN $^{2}$
JUDITH ANDERSON

\section{CORRESPONDING AUTHOR}

SOPHIA DYWILI School of Nursing, Midwifery and Indigenous Health, Faculty of Science, Charles Sturt University, Locked Bag 588, Wagga Wagga NSW 2678 Australia.

Phone: +61 26933 2452. Email: sdywili@csu.edu.au

\section{ABSTRACT}

Objective: The aim of this paper is to report on the experience of racial discrimination by black sub-Saharan overseas qualified nurses working in rural Australia.

Background: The arrival of black African people as skilled professional migrants is relatively new in rural Australia. The presence of black sub-Saharan African nurses in Australian healthcare facilities is changing the face of the Australian nurse. Australia, like other developed countries, has been receiving migrant nurses from the African continent in a bid to reverse its critical nurse shortage. Literature has shown that globally, overseas qualified nurses of colour have encountered work challenges that have included racial discrimination.

Study design and methods: A qualitative hermeneutical phenomenological approach was used. Eighteen nurses were purposively selected using personal invite and a snowballing technique. Data collection involved individual face to face interviews and a focus group discussion.

Results: The exploration of experiences revealed issues of race and colour among colleagues and between patients and overseas qualified nurses. Overseas qualified nurses experienced incidents of
1 School of Nursing, Midwifery \& Indigenous Health, Charles Sturt University, NSW, Australia.

2 Professor of Nursing (Mental Health), University of Newcastle, NSW, Australia.

3 College of Health and Medicine, University of Tasmania, TAS, Australia. 
Nurse managers need to be more vigilant in monitoring staff interactions in their Units. Understanding and support for diversity at the workplace by all nurses will improve patient and staff safety.

Keywords: Overseas qualified nurse, African nurses, discrimination, resilience, teamwork.

\section{What is already known about the topic?}

- There is a global shortage of nurses. Nurse migration between countries has been taking place for a long time, and the trend will continue.

- Discrimination against migrant nurses of colour has been identified in various destination countries.
What this paper adds:

- Findings from this study suggest existence of racism against black sub-Saharan African nurses in rural Australian workplaces.

- Black sub-Saharan African nurses need more support from nurse managers. They may get this through close monitoring of staff interactions in the workplace and intervention when racism is noted.

- Black sub-Saharan African nurses showed resilience in overcoming adversity in their workplace.

\section{BACKGROUND}

Migration of nurses between countries has been taking place for decades; and it is increasing. For the period 2011 to 2016 the number of foreign-trained nurses working in Organisation for Economic Co-operation and Development countries increased by $20 \%{ }^{1}$ A critical global shortage of nurses, including in Australia, has resulted in an increase in migration where economically advantaged countries have increasingly depended on the recruitment of overseas qualified nurses. ${ }^{2-5}$ Globalisation has facilitated this movement of nurses across international borders. Australia has received an increasing number of overseas qualified nurses from the African continent in recent years as the country wrestled with a nursing shortage particularly in their rural communities. ${ }^{5-10}$

Literature has shown extensive exploration of the experiences of overseas qualified nurses in their destination countries, Australia included. ${ }^{11-17}$ However, literature shows minimal discussion of the experiences of overseas qualified nurses in the rural areas of their destination countries, ${ }^{8,18}$ much less the unique experiences of African nurses working in rural Australia. ${ }^{18}$ The ongoing dialogue regarding international nurse migration has been silent and has shown a gap regarding the experience of African nurses who migrated to rural Australia. Hence, this study explored the migration experiences of sub-Saharan African overseas qualified nurses living and working in rural Australia.

The three research questions that guided the study were:

1. What was the experience of the sub-Saharan African overseas qualified nurses as they migrated from their countries to rural Australia?

2. What is the experience of sub-Saharan African overseas qualified nurses as they live and work in rural Australia?

3. From the sub-Saharan African overseas qualified nurses' perspective, what does it mean to be a registered nurse living and working in rural Australia?
While overseas qualified nurses, who are usually in the minority, have benefitted from their migration, they have also faced some challenges in their destination countries. These challenges have included communication and cultural barriers, underutilisation of their skills and experiences of racial discrimination. ${ }^{16,19-22}$ This paper reports on data that relates to the early migration experiences which were part of a broader study that was investigating the overall experiences of sub-Saharan African overseas qualified nurses working in rural Australia.

\section{METHODS}

This study methodology used hermeneutic phenomenology as the underpinning philosophy. Hermeneutic inquiry, as suggested by Heidegger and expanded by Gadamer guided the methodology as it enabled the exploration and interpretation of the experiences of overseas qualified nurses as they migrated and lived in rural New South Wales. ${ }^{23,24}$ Hermeneutic phenomenology allowed participants to relate their stories. This approach allowed understanding of the nurses' migration life as experienced rather than conceptualised. ${ }^{25}$ With regards to the concept of stateof-being in hermeneutic phenomenology, the presence of overseas qualified nurses in rural New South Wales was their state of being-in-the world. The hermeneutic phenomenological approach helped interpret the participant meaning of their being overseas qualified nurses in rural Australia. This interpretive paradigm allowed use of research methods that generated dialogue with participants.

\section{THE PARTICIPANTS}

The focus of the study was sub-Saharan African overseas qualified registered nurses working in rural New South Wales (NSW) who had migrated to Australia using the General Skilled Migration visa (Sub Class 457). A snowballing technique was used to purposively select 18 participants. ${ }^{26}$ 
An initial invitation advertisement in a local newspaper yielded no responses. The lead author directly approached the first three participants who were attending African cultural functions, to inform them of the study. These participants then referred prospective participants to the researcher and those prospective participants who were interested in participating in the study contacted or offered their contact details to the researcher. The numbers increased through snowballing.

Only black sub-Saharan African nurses responded to the invitation. Their home countries were former British colonies in Africa; English was one of the official languages of communication in their countries. Only one participant was male. Their professional experience and migration status are as shown in Table 1 . All participants on the table were deidentified; those from individual interviews were given pseudonyms.

All participants had resigned from their fulltime employment as registered nurses when they left their countries for Australian jobs; with some having given up senior positions for example, clinical nurse educator and district nursing officer positions in their countries of origin. At the time of interviews all participants worked fulltime as registered nurses at either a public hospital or at an aged care facility. Some participants had moved from aged care facilities to hospitals. A few participants also worked as casuals outside their place of fulltime employment. None had been promoted to a senior level.

\section{DATA COLLECTION}

Data were collected in 2014 by the lead author via individual face to face interviews which were conducted in participant homes and one focus group discussion that was composed of participants who were not interviewed individually. A trial of the interview process was conducted between the lead author and one of the research supervisors prior to data collection. Semi-structured interviews and prompts to bring the discussion back to the study questions were used whenever required; otherwise participant stories guided the interviews. The use of focus group discussion fitted in well with Gadamer's philosophy of dialogue and fusion of horizons as this brought participants together allowing them to share experiences. ${ }^{24}$ Focus groups assist in recalling information and they allow for development of group dynamics that can be synergistic in collecting information that may have not come up in one-to-one interviews. This approach was congruent with the African culture where people traditionally embrace discussion of life issues in gatherings. ${ }^{27}$ The lead author who, by virtue of being an overseas qualified nurse from the same continent, shared similar ethnic and professional background, conducted the interviews which were approximately an hour in duration. Though the investigator had their own pre-understandings and migration experiences within the hermeneutic circle from their historicity, staying open during data analysis helped them to see things differently, expanding their horizons on the phenomenon. The investigator did not impose their own knowledge or experience on the migration stories narrated

TABLE 1: DEMOGRAPHICS OF PARTICIPANTS AT TIME OF INTERVIEW.

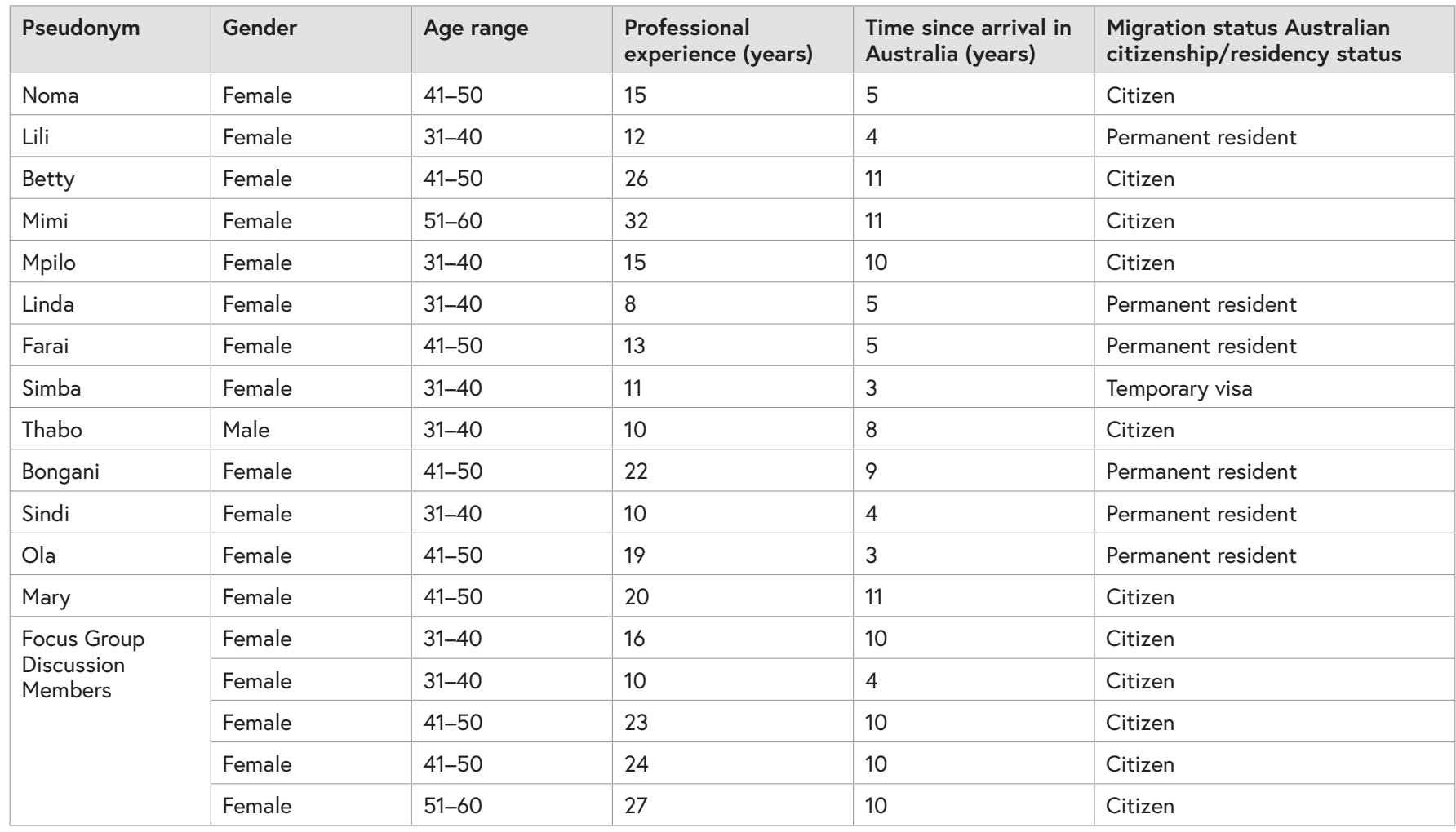


by participants but expanded their own understanding of what it was like for other migrant nurses.

\section{DATA ANALYSIS}

Data from the recordings were organised and managed using the NVivo 10 software package..$^{28}$ The data were analysed as guided by Spiegelberg and Schuhmann's essentials in phenomenological investigations and Streubert's steps on data analysis. ${ }^{29,30}$ The authors read the transcripts and listened to recordings several times, and then categorised the data according to the themes that were emerging. This rereading and moving back and forth between the transcripts and the emerging interpretations was guided by the circular nature of hermeneutic analysis. 23,24 The immersion in the data allowed the authors to identify patterns as they engaged with the data. ${ }^{31}$ The interpretation and final themes were agreed upon by all authors. Although participants told unique individual stories, interviews were stopped when the stories of the last two individual interviews showed a similar pattern to previous interviews.

Involvement of participants who experienced the study phenomenon increased the trustworthiness of the findings. Interviews were conducted by one researcher in order to strengthen dependability of findings and, the researcher remained open to different opinions to avoid personal distortions interfering with findings. The paper includes verbatim sections of participant stories so that their voices may surface. Transcripts were verified by participants.

\section{ETHICAL CONSIDERATIONS}

Ethics approval to undertake the study was obtained from the University Human Research Ethics Committee. The participants were a minority group within the Australian health workforce and, were considered vulnerable and marginalised and there was the potential for emotional distress from re-living some of their experiences. Participants were informed of the voluntary nature of the study and that they could terminate the discussion if they became distressed during the interview. They contacted the researcher after being informed about the study. Participants were assured of confidentiality. Names have been changed for interview extracts in order to ensure confidentiality.

\section{RESULTS}

The paper presents findings relating to early experiences which included participant arrival in Australia and their experience of early interaction with colleagues and patients as they settled into their workplaces. Participants described their positive experiences with management as they arrived in Australia, and the negative experiences as they settled into their new jobs in the clinical area. The presentation of the findings is illustrated with the voices of participants as they describe their experiences of starting a new life in Australia.

\section{ARRIVAL EXPERIENCE}

Reasons given by overseas qualified nurses for migrating to Australia related to socioeconomic decline in their countries, political and family factors as well as perceived opportunities for career advancement. Participants were welcomed by their migration agents and employers as they arrived in Australia. Participants were happy and excited with their reception by managers and Agents at airports and train stations as it provided for a smooth arrival. In some instances, the welcoming team included the hospital directors of nursing:

When I arrived at the train station, they were really nice; there were four of them waiting for me. It was so beautiful and they had flowers ... The Director of Nursing and management staff were really nice, and they tried to make sure that I settled really well. (Mpilo)

The DON [Director of Nursing] and District Nurse Educator made us feel very welcome...Yeah, they were all ready for us ... The [reception] was good; people were quite willing to help us ... There was a newspaper article on us; ... so even the community was prepared to help us. (Mimi)

At the airport, the hospital manager and my manager were holding my name; they were there with MY name! [In the house] I had a small fridge which was filled up ... The following day they were driving me around showing me the town; that was nice. (Bongani)

The overseas qualified nurses were humbled by the welcoming preparations made for them. They received positive support from their managers and some of their colleagues. Participants largely saw positives in their migration to Australia. However, they quickly encountered unexpected challenges in the workplace which, participants felt, were based on racial differences.

\section{FEELING UNWELCOME IN THE WORKPLACE}

For the first few months of her starting work, Farai felt unwelcome by colleagues she perceived as not wanting to interact with her:

You could see there were staff who didn't want to see you ... there were racists among the staff... some of them didn't even want you to touch their cup. Even if you went to the staff room sometimes you were isolated. They didn't even want to associate with you. (Farai)

Similarly, their patients showed discomfort in being nursed by black nurses:

There is also the issue of working with patients who have never been exposed to blacks ... I was on night shift and I remember a patient who screamed when I went to her room. I said, "It's only me, I'm just checking on you”. Then, when I went back the second time, she screamed, "Aaaaahhh!" I said, "Oh, why?" she said, "It's you”. "What have I done?" "I'm scared of you”. "What's wrong?” "Because you're black”. (Focus Group Discussion) 
Many of these incidents were not reported to management as some of the African nurses involved felt they needed to deal with these issues alone. Some instances concerned relatives of patients who did not want their loved ones to be looked after by a black nurse. In this instance the African nurse was attending to a patient with a white nurse:

She [relative] said to the nurse I was working with, "Excuse me nurse, I don't want my mother to be nursed by a black person ... in our family we don't do that; we don't associate with them". I was there!! But because we had a supportive Nurse Unit Manager, she made sure that I kept on looking after the mother until the relative ended up liking me. (Focus Group Discussion)

The participant did not like what her patient's relative said especially in her presence. The participants also did not like how, soon after arrival, they would be asked when they would return to their countries. Such discriminatory questions gave participants a feeling of being unwelcome in Australia.

\section{FEELING UNDERVALUED AND NOT TRUSTED IN THE WORKPLACE}

Participants felt they were not trusted nor were their nursing skills recognised or valued by their colleagues and patients. There were instances when participants needed to convince patients that they were receiving appropriate care; that it was just the difference of skin colour, as they could do whatever anyone with white skin could do.

When we were new here and doing the medication round,... they didn't take the medication ... and then when an Australian girl passed through, they would ask her if they should take that medication and then they took it ... Obviously, you knew that they didn't take the medication because they didn't trust you. (Mpilo)

Participants attributed this to their being of African origin. Participants also felt their colleagues did not trust them either and attributed this mistrust to racism:

It [racism] will always be there, ... I remember the times when I was in charge [of a shift], the doctors would come and talk to my juniors, then those juniors would come and give me the orders; until I started saying, "I'm not taking any orders from anyone. If the doctors want to tell me anything they can come and talk to me, I do understand English". That's when it stopped. Otherwise, it was just someone talking to someone else and then me. (Focus Group Discussion)

As this participant in the focus group indicates, participants generally felt that they needed to deal with such issues themselves. However, sometimes this mistrust resulted in 'dobbing in' due to doubts and suspicion among staff:

There was a lot of 'dobbing in'... people going to the office ... and then there were those, of course, who were looking for errors in everything you did. Yeah, but anyway, we soldiered on. (Thabo)
Other participants felt their colleagues were sceptical about their performance as registered nurses:

Ahh, these people... they treated me like trash when I started here, I used to be so stressed with the way things were going on; I would cry. (Sindi)

Despite such a reaction, Sindi felt unable to ask managers for assistance to deal with such issues. Some staff under the supervision of overseas qualified nurses were defiant and not respectful of their positions of authority:

... and, being a black person, and you're leading Assistants in Nursing, and most of them were Australians. Some of them looked down upon you.... Sometimes you would delegate to the staff and the staff wouldn't do it, you ended up doing it yourself. They didn't expect an African to be educated and come in and work as their team leader... I remember when I asked one of the cleaners to come and clean in the office because the bin was spilling over,... and then she said, "Do you think you can tell me what to do?"(Farai)

This insubordination was interpreted by Farai as due to her being black and of African origin. She felt her professional skills and supervisory position were not valued, not even by a general worker. The mistrust made it very hard for participants to render nursing care as they would seek help from enrolled nurses or assistants in nursing to convince patients that they were receiving correct medications. Their patients did not mind black nurses providing them with lower level personal care though.

Participants detailed situations where they were hindered from professional development courses particularly those run by the College of Nursing and sponsored by their hospitals. They claimed that local nurses got information before they did, and the spots would be full by the time they applied. They were also not happy with the promotion processes. Betty was one of the participants who had been in Australia for some years having come with many years of nursing experience. They felt frustrated for being sidelined for promotional opportunities, without consideration for their professional experience:

As registered nurses, they should give us chances to be promoted as well ... Why are they taking so long to promote us? It is very annoying because we also want those promotions.... When you ask why I am not being promoted they tell you, "Oh! it's because we're still trying to see how much you can do". How much I can do, when I've been mentoring the person that has been promoted? When you go for a [performance] appraisal every box is ticked, so you wonder why. (Betty)

Participants wanted to be allowed to advance in their chosen careers just like everyone else, more so for those who had migrated for that purpose and felt discriminated against when this did not occur. Although some of this discrimination came from subordinates and peers, when it came from managers it was reinforced to the participants 
that assistance to deal with it would not be forthcoming. For this reason, some participants did not act through the organisational hierarchy.

\section{COPING WITH BEING SEEN DIFFERENTLY}

The participants identified various coping strategies as they responded to the discrimination by their colleagues and patients. Some participants suggested alternative carers for their patients:

Sometimes you find clients who are racist as well and I would say, "OK, if you don't want me to look after you I will find someone else to look after you because I can't change who I am". So yeah, it's unfortunate really. (Sindi)

Others decided to stay out of the spotlight and would block their minds of the negative behaviours and focus on their migration goals:

It's like, we knew why we came here, ... so you know, you can't go back because of those situations and you also want your children to have a better life here, to have a better education; so, you sort of ... [pause] ... humble yourself; I can say accept, telling yourself you're just here to work and you just do; yes, you do your work and then go home. (Focus Group Discussion)

Still others would not accept this so easily without countering these racist behaviours; they reciprocated the negative behaviours and, this impacted patient care:

In our ward, it's each man for himself and God for us all. No one is willing to help you with heavy loads. It's your patients, it's your problem; you have to deal with it. In our ward, there's a 'float' person but the floating part of it is selective... They choose the 'white area' [where the white nurses are allocated]. Yeah, they go to the 'white area' and leave the 'black area'... and you just suffer by yourself. But now I also do that too; when I've got my black ones, I go to the 'black area' to help with heavy patients. What can you do? Once you point it out, you get labelled. (Focus Group Discussion)

The 'float' person was expected to assist nurses with heavier patient loads during the shift. However, participants observed that this help was offered selectively as it was based on the colour of the nurse. This behaviour by the float person adversely affected not only the nurse, as this stressed them physically and mentally, but also patient care. According to participants, these racially based behaviours occurred on a day-to-day basis, exposing them to an adversity that threatened their newly acquired jobs and mental health. Some participants downplayed such incidents without officially reporting incidents to authorities. Participants would reach out and support each other including organising social functions together for opportunities to destress and improve their resilience.

The findings above show participants perceiving their experience as being positively welcomed by their managers while they were largely not welcome or trusted by some of their colleagues and patients. They felt their professional skills were not valued. Participants reacted differently in adjusting to these negative responses.

\section{DISCUSSION}

This study explored the migration experience of subSaharan African overseas qualified nurses in rural New South Wales. As results have shown, the nurses were welcomed by management, however, as they entered their workplaces in hospitals and aged care facilities, they experienced discrimination and disadvantage based on their race and skin colour. Their experiences have shown the power of welcoming, the existence of discrimination by race at their healthcare facilities as well as showing the importance of trust and teamwork at the workplace. Participants described various ways of coping with the negative responses they received from their colleagues and patients. They have also shown their resilience and determination to achieve their migration goals as they have not relented.

Welcoming others is the right thing to do; this gesture significantly impacts the life of newcomers as they feel they are valued, and they belong. ${ }^{32}$ The reception of overseas qualified nurses by their employers emphasised the power of welcoming migrants into a new country and how that lays the foundation for them to feel secure and accepted in their new land. Overseas qualified nurses will work better in an environment where they feel welcome. Literature on migration has highlighted the importance of welcoming people to their new country. $33-36$ Through multicultural groups and the Refugee Council of Australia, the country has committed to welcoming new migrants and supporting cultural diversity. ${ }^{37}$ Föbker, Temme, and Wiegandt noted that skilled migrants are attracted to countries with a welcoming work culture. ${ }^{38}$ The welcome these nurses received made them feel at home.

\section{RACE AND COLOUR: BEING VISIBLY DIFFERENT}

The presence of the visibly different African registered nurses in Australian healthcare facilities is relatively new and, has changed the face of the Australian nurse. The participants were black nurses from sub-Saharan Africa. They spoke English with a different accent from the Australian one. The differences were visible for everyone to see. Colic-Peisker and Hlavac noted that where black people are a minority they will be 'visibly different' for everyone to see. ${ }^{39}$

Participants attributed their feelings of being unwelcome and discriminated against by some of their colleagues and patients to their being of different colour and coming from Africa. It did not matter how much nursing experience the participants had, they were still marginalised by some of their colleagues and patients. They felt as outsiders, that they did not belong. This resulted in loneliness and stress. 
Discrimination based on racism has been reported in studies of overseas qualified nurses.,40-42 Moyce, Lash and de Leon Siantz echoed similar findings on racism and discrimination where nurses have attributed this to their skin colour. ${ }^{19}$ The Australian situation is not a new phenomenon for black Africans to be excluded. The sources of discrimination are similar in all studies; these being from patients and their relatives, colleagues and sometimes supervisors.

Discrimination based on race has no place in the nursing workforce. It is a result of people who are not aware of the beauty of diversity and the fact that it should instead be celebrated. Celebrating diversity incorporates understanding, respecting and accepting everyone as unique and recognising their differences regardless of race. At organisational level it drives innovation and excellence. 43 These African nurses added to the cultural diversity in the nursing workforce. Colleagues could have taken advantage of and gained from the nursing experience the participants had and the cultural diversity they provided; unfortunately, this was a missed opportunity for all, particularly at a time when society is becoming more culturally diverse. The multicultural activities that take place in various communities to promote harmony and social cohesion can serve as a platform for the nursing workforce/healthcare institutions to similarly celebrate diversity in workplaces and to bring staff together. ${ }^{44}$ Healthcare sector staff need to treat overseas qualified nurses of colour as colleagues. Australia is known for its good spirit of multiculturalism. The Australian Indigenous philosophy of life, yindyamarra winhanganha -'the wisdom of respectfully knowing how to live well in a world worth living in' blends in well with the African philosophy of Ubuntu, ${ }^{45}$ the spirit that drives humaneness and, which encompasses respect, kindness, trust, caring, generosity, community and sharing. ${ }^{46,47}$ These life philosophies emphasise respect for each other and they challenge us to live well in a world that is worth living in.

\section{MISTRUST AND BEING UNDERVALUED}

The issue of not being trusted by patients and colleagues could have negatively impacted the nursing care given by overseas qualified nurses. Trust among team members builds teamwork. Positive nursing care outcomes are built on trust between nurses and patients. It is near impossible for teams to share the same values and common goals when trust is conditional..$^{8}$ Team members can only respect and accept each other through trust. It is the trust that strengthens interpersonal relationships and binds teams together. Team members experience a feeling of belonging in a trusting environment and, the resultant team collaboration helps achieve better patient health outcomes. Participants were not trusted by their colleagues and patients. Colleagues needed to value their professional knowledge and experience and, their supervisors could have trusted their potential to advance in their profession. Participants needed to belong to this team; to be seen beyond their dark skin. This mistrust may have explained the judgement participants received where doctors and patients sought third party assistance to interact with them. Participants interpreted this as racism.

The findings of being undervalued and not being welcome by some of their colleagues and patients are similar to those of Likupe and Archibong and Likupe in the UK National Health Service where black African nurses faced racism, discrimination and unequal opportunities.40,49 This was confirmed by nurse managers who participated in their study. However, findings on professional development differed from those of Likupe where African nurse migrants in the UK were described as not 'bothered about developing themselves' (p. 237).49 Participants in this study have shown their desire to take up courses as well as promotion opportunities and, have struggled to overcome the hindrances. It should be noted that some participants had migrated for career advancement purposes.

\section{RESILIENCE AND PERSISTENCE}

Participants needed to work harder to be accepted as professionals in their own right. They were not giving up on their hopes and aspirations; they remained resilient and persistent as they were determined to achieve their migration goals. Mansouri and Lobo noted that individuals who are racially discriminated against can get more resilient.50 Participants needed to remain optimistic and draw on their individual tenacity to overcome. After all, going back was not an option for most of them. The position by management not to tolerate any form of discrimination of the overseas qualified nurses by anyone helped participants to maintain their resolve to soldier on at their workplace.

In accordance with Section 7 of the Anti-Discrimination Act 1977 and other institutional policies, ${ }^{51}$ Australian health institutions do not sanction discrimination at the workplace. However, participants still felt excluded by their colleagues and patients. Essed, ${ }^{52}$ asserted that racism is not always overt; it can be integrated into everyday practices without being questioned, particularly if it is seen as normal by the

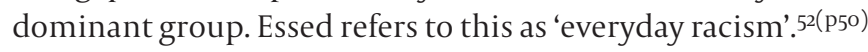
For participants, it was these 'everyday' interactions that hurt the most.

It seems the issue here was not just being an overseas qualified nurse; it was about being black and being an undesirable. Regardless of participants possessing the required qualities and skills, some people had problems with this dark skin. The subtle discriminatory behaviours of patients and their relatives avoiding care from black nurses, nurses not providing help to their black colleagues with heavier workloads or managers limiting opportunities for black nurses to advance their careers, is not acceptable. The rejection of their nursing care by patients had nothing to do with their competence. They were qualified registered 
nurses, they were registered with Nurses and Midwives Board of Australia and, some of them brought with them many years of postgraduate nursing experience. Such behaviours impacted the participants' trust in their capabilities, undermining their self-esteem. It is accepted that patients may have experienced cultural shock in being nursed by black nurses as some of these overseas qualified nurses were the first ones to work in those institutions. Black nurses were a new skilled migrant group in rural Australia; this may have increased their visibility. Alexis noted that nurses from Africa faced more discrimination and tended to receive less help compared to other overseas qualified nurses. 53

Participants also showed an element of silence regarding everyday racism. They downplayed such incidents or developed their own coping mechanisms without officially reporting incidents to authorities, authorities that had declared no tolerance for racism or violence. This silence on everyday racism confirms similar findings by Essed and Mapedzahama et al.52,7 Mapedzahama et al described racism in the workplace as a form of violence. ${ }^{7}$ Nurses facing discriminatory behaviours based on race need to speak up against this violence.

\section{IMPLICATIONS FOR RESEARCH, POLICY AND PRACTICE}

Results of this study give new insights into the experience of sub-Saharan African overseas qualified nurses in rural Australia. Even though health services did not tolerate racism, more proactive processes could have been put in place to identify and prevent such racist intolerance. Nurses and nurse managers need to acknowledge that racial discrimination exists in their Units. Nurse managers could closely monitor professional practices in their Units and, be more alert in identifying these negative interactions among patients and nurses from different ethnic backgrounds. These incidents may be happening below their radar. Nurse managers could allow regular debriefing sessions for their staff to mitigate disadvantage and discrimination based on race. Black sub-Saharan African overseas qualified nurses are put at greater risk for errors if their professional competencies are always questioned.

A workplace that promotes teamwork is a safe working environment. There is need to invest in teamwork and cultural diversity training and to support the overseas qualified nurses especially in their first few months of arrival. The local multicultural health services could help with involving healthcare staff in their multicultural social events to facilitate racial integration. Further research focussing on the effectiveness of such initiatives would be useful.

Given that Australia still needs to continue recruiting overseas qualified nurses to sustain their nursing needs, there is need for healthcare staff to accommodate these nurses as colleagues and recognise their contribution to the Australian healthcare system. Early integration is important to their overall migration experience. Australia is a multiracial society that should be strengthened by diversity. Black sub-Saharan African overseas qualified nurses need more workplace support due to the discrimination and disadvantage they tend to face.

Policies that monitor and assess negative interactions between nursing staff could be put in place. The support should be aimed at making the first few months at their new workplace the most memorable. Further exploration of experiences in other geographical areas may be useful for comparison.

\section{STRENGTHS AND LIMITATIONS}

A strength in this study was that all data were collected by the lead researcher who is a black sub-Saharan African nurse migrant herself leading to better understanding of the conversations. The fusion of horizons between the researcher and participants allowed a clear dialogue and interpretation of their experiences. It was not by design that the participants in the study were all black nurses; they self-selected through the snowballing process. The study was open to all sub-Saharan African overseas qualified nurses, but the absence of participants from other races deprived the study of their experiences.

\section{CONCLUSION}

The evidence suggests that there are pockets of racial discrimination that need to be checked in the Australian healthcare system. Under the Anti-Discrimination Act 1977, it is unlawful to discriminate against other persons based on race; and that includes the black African race. Institutional policies have expressed zero tolerance to all forms of violence particularly towards the Australian Indigenous peoples. There is another black face now in the workplace. Such violence undermines the confidence of black African nurses in their professional practice. Findings indicated that there were nurses who did not engage in such behaviour, nurses who saw and heard these racist incidents but did not act to prevent them. A little more support would move those nurses a little higher above being just nonracist and being responsive to such incidents. While the detailed experiences show the extent of discrimination and disadvantage, they also show the determination of participants in overcoming and achieving their migration goals. It is important for managers to be vigilant in monitoring staff interactions.

Author's Institutional Affiliation: Charles Sturt University.

Ethics: The study was approved by Charles Sturt University Human Research Ethics Committee. Ethics Approval No.: 2012/191.

Acknowledgments: The authors would like to thank the subSaharan African overseas qualified nurses for participating in the study. 


\section{Conflict of Interest statement (for all authors):}

No conflict of interest

Funding or sources of support in the form of grants, equipment, drugs etc. No funding was received for this project.

\section{REFERENCES}

1. Organisation for Economic Co-operation and Development (OECD). Recent trends in international migration of doctors, nurses and medical students. 2019. Available from: https://doi.org/10.1787/5571ef48-en

2. Paul JA, MacDonald L. Modeling the benefits of cross-training to address the nursing shortage. Int J Prod Econ. 2014; 150 83-95

3. Stankiewicz G, O'Connor M. Overseas qualified nurses in Australia: reflecting on the issue. Aust J Adv Nurs. 2014; 31(3): 32-8

4. Buchan J, Wismar M, Glinos I, Bremner J. Health professional mobility in a changing Europe: new dynamics, mobile individuals and diverse responses. World Health Organization. Geneva. 2014

5. Chun Tie Y, Birks M, Mills J. The experiences of internationally qualified registered nurses working in the Australian healthcare system: an integrative literature review. J Transcult Nurs. 2018; 29(3): 274-84

6. Blake N. Nursing migration: issues of equity and balance. People Place. 2010; 18(2): 19-24.

7. Mapedzahama V, Rudge T, West S, Perron A. Black nurse in white space? Rethinking the in/visibility of race within the Australian nursing workplace. Nurs Inq. 2012; 19(2): 153-64.

8. Wellard SJ, Stockhausen LJ. Overseas trained nurses working in regional and rural practice settings: do we understand the issues? Rural Remote Health. 2010; 10(3): 1-11.

9. Dywili S, Bonner A, O'Brien L. Why do nurses migrate? A review of recent literature. J Nurs Manag. 2013; 21(3): 511-20

10. Negin J, Rozea A, Cloyd B, Martiniuk ALC. Foreign-born health workers in Australia: an analysis of census data. Hum Resour Health. 2013; 11:69.

11. Beaton M, Walsh J. Overseas recruitment: experiences of nurses immigrating to Newfoundland and Labrador, 1949-2004. Nurs Inq. 2010; 17(2): 173-83

12. Hatzidimitriadou E, Psoinos M. Cultural health capital and professional experiences of overseas doctors and nurses in the UK. Divers Equal Health Care. 2014; 11(1): 35-47.

13. Kishi Y, Inoue K, Crookes P, Shorten A. A model of adaptation of overseas nurses. J Transcult Nurs. 2014; 25(2): 183-91.

14. Mazurenko O, Gupte G, Shan G. A comparison of the education and work experiences of immigrant and the United States of America-trained nurses. Int Nurs Rev. 2014; 61(4): 472-8.

15. Primeau MDP, Champagne FP, Lavoie-Tremblay MP. Foreigntrained nurses' experiences and socioprofessional integration best practices: an integrative literature review. Health Care Manag. 2014; 33(3): 245-53

16. Zhong Y, McKenna L, Copnell B. What are Chinese nurses' experiences whilst working overseas? A narrative scoping review. Int J Nurs Stud. 2017; 74: 101-11.
7. Ghazal LV, Ma C, Djukic M, Squires A. Transition-to-U.S. practice experiences of internationally educated nurses: an integrative review. West J Nurs Res. 2020; 42(5): 373-92.

18. Dywili S, Bonner A, Anderson J, O' Brien L. Experience of overseas-trained health professionals in rural and remote areas of destination countries: a literature review. Aust J Rural Health. 2012; 20(4): 175-84

19. Moyce S, Lash R, de Leon Siantz ML. Migration experiences of foreign educated nurses: a systematic review of the literature. J Transcult Nurs. 2016; 27(2): 181-8.

20. Marcus K, Quimson G, Short SD. Source country perceptions, experiences, and recommendations regarding health workforce migration: a case study from the Philippines. Hum Resour Health. 2014; 12.

21. Mapedzahama V, Rudge T, West S, Kwansah-Aidoo K. Making and maintaining racialised ignorance in Australian nursing workplaces: the case of black African migrant nurses. Australas Rev Afr Stud. 2018; 39(2): 48-73.

22. Tuttas CA. Perceived racial and ethnic prejudice and discrimination experiences of minority migrant nurses: a literature review. J Transcult Nurs. 2015; 26(5): 514-20.

23. Heidegger M. Being and time Oxford. United Kingdom: Blackwell; 1962

24. Gadamer H-G. Truth and method. New York: Seabury Press; 1975

25. Van Manen M. Researching lived experience: human science for an action sensitive pedagogy. London, Ontario: Althouse Press; 1997.

26. DePoy E, Gitlin L. Introduction to research: understanding and applying multiple strategies. 5th ed. St Louis: Elsevier. 2015.

27. Nesbitt P. Indaba! A way of listening, engaging, and understanding across the Anglican communion. New York: Church Publishing; 2017

28. O'Leary Z. The essential guide to doing your research project. Los Angeles: Sage Publications; 2010

29. Spiegelberg H, Schuhmann K. The phenomenological movement: a historical introduction. Dordrecht: Kluwer Academic; 1994.

30. Streubert HJ, Carpenter DR. Qualitative research in nursing: advancing the humanistic imperative. 5th ed. Philadelphia: Lippincott Williams \& Wilkins; 2011

31. Hoover RS, Koerber AL. Using NVivo to answer the challenges of qualitative research in professional communication: benefits and best practices tutorial. IEEE Trans Prof Commun. 2011; 54(1): 68-82.

32. Welcome to Australia. Welcome to Australia annual report: July 2015 - December 2016. Welcome to Australia Ltd. 2016. Available from: https://cdn.welcometoaustralia.org.au/ media/2017/05/26184027/WTA-Annual-Report-201516.pdf

33. Camozzi I. Migrants' associations and their attempts to gain recognition: the case of Milan. Stud Ethn Natl. 2011; 11(3); 468-91.

34. Hyunjoo J. Let their voices be seen: exploring mental mapping as a feminist visual methodology for the study of migrant women. Int J Urban Reg Res. 2014; 38(3): 985-1002.

35. International Organization for Migration. World migration report 2015 - Migrants and cities: new partnerships to manage mobility. 2015. Available from: https://www.iom.int/worldmigration-report-2015

36. Refugee Council of Australia. Australia's response to a world in crisis. Refugee Council of Australia. 2015. Available from: http://www.refugeecouncil.org.au/ 
37. Lobo M. Gestures of judgement and welcome in public spaces: hypervisible migrant newcomers in Darwin, Australia. J Cult Geogr. 2015; 32(1): 54 - 67.

38. Föbker S, Temme D, Wiegandt CC. A warm welcome to highlyskilled migrants: how can municipal administrations play their part? Tijdschr Econ Soc Geogr. 2014; 105(5): 542-57.

39. Colic-Peisker V, Hlavac J. Anglo-Australian and non-Anglophone middle classes: 'foreign accent' and social inclusion. Aust J Soc Issues. 2014; 49(3): 349-71.

40. Likupe G, Archibong U. Black African nurses' experiences of equality, racism, and discrimination in the National Health Service. J Psych Iss Org Cult. 2013; 3(S1): 227-46.

41. Rolle Sands S, Ingraham K, Salami BO. Caribbean nurse migration-a scoping review. Hum Resour Health. 2020; 18(1): 1-10.

42. Timilsina Bhandari KK, Xiao LD, Belan I. Job satisfaction of overseas-qualified nurses working in Australian hospitals. Int Nurs Rev. 2015; 62(1): 64-74.

43. Anseth KS. Embracing and celebrating diversity. MRS Bull. 2016; 41(11): 829-31.

44. Multicultural NSW. Communities of New South Wales. Multicultural NSW. 2020. Available from: https://multicultural. nsw.gov.au/communities/

45. Grant S, Rudder J. A new Wiradjuri dictionary: English to Wiradjuri, Wiradjuri to English, categories of things and reference tables. Canberra: Restoration House; 2010.

46. Gade CBN. What is Ubuntu? Different interpretations among South Africans of African descent. S Afr J Phil. 2012; 31(3): 484-503.

47. Ncube LB. Ubuntu: A transformative leadership philosophy. J Leadersh Stud. 2010; 4(3): 77-82.

48. Costa AC, Anderson N. Team trust. In: Salas E, editor. The Wiley Blackwell handbook of the psychology of team working and collaborative processes. Hoboken: Wiley-Blackwell; 2017; 393-416.

49. Likupe G. Experiences of African nurses and the perception of their managers in the NHS. J Nurs Manag. 2015; 23(2): 231-41.

50. Mansouri F, Lobo M, editors. Migration, citizenship, and intercultural relations: looking through the lens of social inclusion (Studies in migration and diaspora). Farnham, United Kingdom: Ashgate Publishing; 2011.

51. Anti-Discrimination Act 1977 (NSW) No. 48 s 7. Available from: https://www.legislation.nsw.gov.au/view/html/inforce/current/ act-1977-048

52. Essed P. Understanding everyday racism: an interdisciplinary theory. Newbury Park, CA: Sage Publications; 1991.

53. Alexis $O$. Internationally recruited nurses' experiences in England: a survey approach. Nurs Outlook. 2015; 63(3): 238-44. 